\title{
Treatment of carcinoma of the bronchus by interstitial irradiation
}

\author{
A study of 198 patients
}

\author{
J R . P . G I B BONS A N D R B A K ER \\ From Brompton Hospital, London, S.W.1
}

\begin{abstract}
One hundred and ninety-eight patients suffering from inoperable carcinoma of the bronchus who have been treated with interstitial irradiation at the Brompton Hospital are reviewed. It has been found that the quality of life of these patients may be improved by this form of treatment and that their life span is increased by it, though not to a statistically significant length, as compared with patients given either radiotherapy or no treatment at all. The advantages over radiotherapy are discussed.
\end{abstract}

Almost the only hope of cure of carcinoma of the bronchus at the present time is by total surgical excision. During the past 15 years at the Brompton Hospital, one in every five patients with carcinoma of the bronchus proved to have an inoperable lesion at thoracotomy despite the fact that the lesion appeared to be operable on clinical, radiological, and bronchoscopic findings. These patients had already been selected from a much larger number suffering from carcinoma of the bronchus who, because of dissemination of the carcinoma, infirmity, or cardiac or respiratory disease, were considered unfit for surgery.

Interstitial irradiation has been used in the treatment of inoperable carcinoma of the bronchus at the Brompton and King's College Hospitals, and 100 patients were reported upon by Johnston, Cleland, and Howard in 1961. In this paper, 198 cases treated in the past 15 years are reported ; 70 of these were included in Johnston's series. All of our patients have been followed up for at least nine months after operation.

\section{DESCRIPTION OF APPARATUS}

Standard size cylinders of gold, measuring $2.5 \mathrm{~mm}$. in length and $0.8 \mathrm{~mm}$. in diameter, are encased in platinum. These grains are irradiated and the radioactive isotope of gold (Au 198) then emits gamma and beta rays. The thin layer of platinum filters off some of the beta rays, which avoids necrosis of tissue close to the source (Johnston et al., 1961). The half-life of Au 198 is $2 \cdot 7$ days.
The gold grains are inserted using an introducer gun designed at the Royal Marsden Hospital (Hodt, Sinclair and Smithers, 1952). Fourteen radioactive gold grains are contained in an aluminium magazine which is enclosed in tin foil. Before insertion into the gun, the level of activity of the grains is measured. The needles, which can be attached to the gun, are of varying lengths, depending on whether the grains are to be inserted at thoracotomy or through a bronchoscope. When the gun is primed the 14 grains lie in the needle and every time the trigger is pulled a grain is ejected into the tumour.

\section{DOSAGE}

The gold seeds used had an activity of between 3.5 and $5 \mathrm{mCi}$. In a retrospective survey it has been difficult to assess the tumour dose given as this, for any given number of gold seeds, varies inversely with the size of the tumour. In many of the early cases the size of the tumour was not recorded. A tumour, $2.5 \mathrm{~cm}$. in diameter, implanted with gold seeds activated to $3.5 \mathrm{mCi}$ would receive about 18,000 rads. It is probable that most of the patients in this series received doses of between 5,000 and 15,000 rads, but we know that our recent cases have received doses of 10,000 to 15,000 rads (an average of 20-40 gold seeds).

In 1961 Johnston et al. aimed at a tumour dosage of about 6,000 rads. Clifton, Henschke, and Silby (1958) have shown that a much higher dosage $(10,000$ to 25,000 rads $)$ is well tolerated, although there is a slight risk of oesophagitis if 
the irradiated growth is near that organ. One must assume that the higher the tumour dosage the greater the benefit to the patient, provided unpleasant side-effects do not occur.

\section{INDICATIONS FOR THE USE OF INTERSTITIAL IRRADIATION}

We considered the indications were as stated in Johnston's article (Johnston et al., 1961).

1. GROWTHS NOT RESECTABLE AT THORACOTOMY Growths which are thought to be operable on clinical, radiological, and bronchoscopic findings are sometimes found to be inoperable at thoracotomy due to invasion of some vital structure such as the aorta, the oesophagus, or the heart.

\section{RESECTABLE GROWTHS BUT RESPIRATORY RESERVE} INADEQUATE FOR RADICAL EXCISION In some patients thoracotomy was done in the hope of removing the carcinoma by lobectomy. Knowing that the patient would not stand pneumonectomy, lobectomy was sometimes not possible due to transgression of the fissures or hilar involvement. Occasionally thoracotomy was done to establish the diagnosis in the presence of a doubtful shadow in the lung, and at the time the extent of the resection necessary to remove the lesion was too great to allow adequate respiration afterwards.

3. AS A SUPPLEMENT TO SURGERY IN PARTIALLY RESECTED GROWTHS A number of cases, often 'superior sulcus' tumours, were treated when it was seen that tumour tissue could not be completely removed at operation. In the first three groups 169 patients were treated with interstitial irradiation.

4. INOPERABLE GROWTHS TREATED BY ENDOBRONCHIAL IMPLANTATION This method was used in tumours which involved the carina or trachea, and occasionally to treat a recurrence at the suture line after a previous lung resection (27 patients were treated in this way).

\section{CONTRAINDICATIONS}

Interstitial irradiation is probably of little value if there are multiple pulmonary and pleural metastases (Ariel, Head, Langston, and Avery, 1949).

\section{CASE REPORTS}

Two patients who show regression of radiological signs, shrinkage of the tumour, and re-aeration of previously collapsed areas of the lung are reported.
CASE 1 A 53-year-old accountant was referred in May, 1966. He had a history of a chronic cough which had been worsening over the past year or two. He occasionally complained of painful swollen ankles but had no other symptoms. In the past 40 years he had smoked 30-40 cigarettes a day.

On clinical examination he was found to have grade 1 clubbing but no other abnormality. A radiograph showed a large mass in the left lung close to the mediastinum. Malignant cells were not found in the sputum and bronchoscopic examination was negative.

A left thoracotomy was performed in June, 1966, and a large mass was found in the anterior segment of the left upper lobe, ulcerating in the subaortic fossa. Biopsy showed this to be an undifferentiated carcinoma. Three magazines of gold grains were inserted giving a total activity of $109 \cdot 2 \mathrm{mCi}$ (Fig. 1).

The patient made a good recovery but had an apparent recurrent nerve palsy after the operation. He has since been seen at frequent intervals and on examination in December, 1967 was found to be very well. His chest radiographs were satisfactory (Fig. 2). There was no evidence on this occasion of any recurrent nerve palsy.

CASE 2 Mrs. M, a 53-year-old clerk and housewife, was well until February 1967, when she began to feel excessively tired on the slightest exertion. By June 1967 she had developed a persistent cough and later produced small amounts of white sputum. She complained of wheeziness and marked shortness of breath on exertion and also occasional tightness across the front of the chest which did not radiate down the arm. There were no voice changes, she did not suffer from winter bronchitis, and never had any haemoptysis.

On clinical examination she was found to have diminished movements and almost no breath sounds in the left chest. Otherwise no other abnormalities were detected.

A routine radiograph showed a mass situated in the left hilar region with a mediastinal shift to the left; the left hemidiaphragm was elevated (Fig. 3).

No neoplastic cells were found in the sputum.

Bronchoscopy showed almost complete stenosis at the level of the left upper lobe bronchus; a biopsy was taken but no frank tumour was seen.

On 31 October a left thoracotomy was performed. A tumour was found filling the aortic fossa and involving the glands below the aorta. There was a big mass in the lung and air was trapped in the lung itself. Two infarcts were present in the upper lobe.

Thirty-nine gold grains $(3.2 \mathrm{mCi}$ each) were inserted into the growth and glandular tissue. A biopsy was taken for histological examination; it was found to be probably of oat-cell type.

The patient's post-operative course was very satisfactory; when discharged from hospital she had air entry on the left side and the radio- 


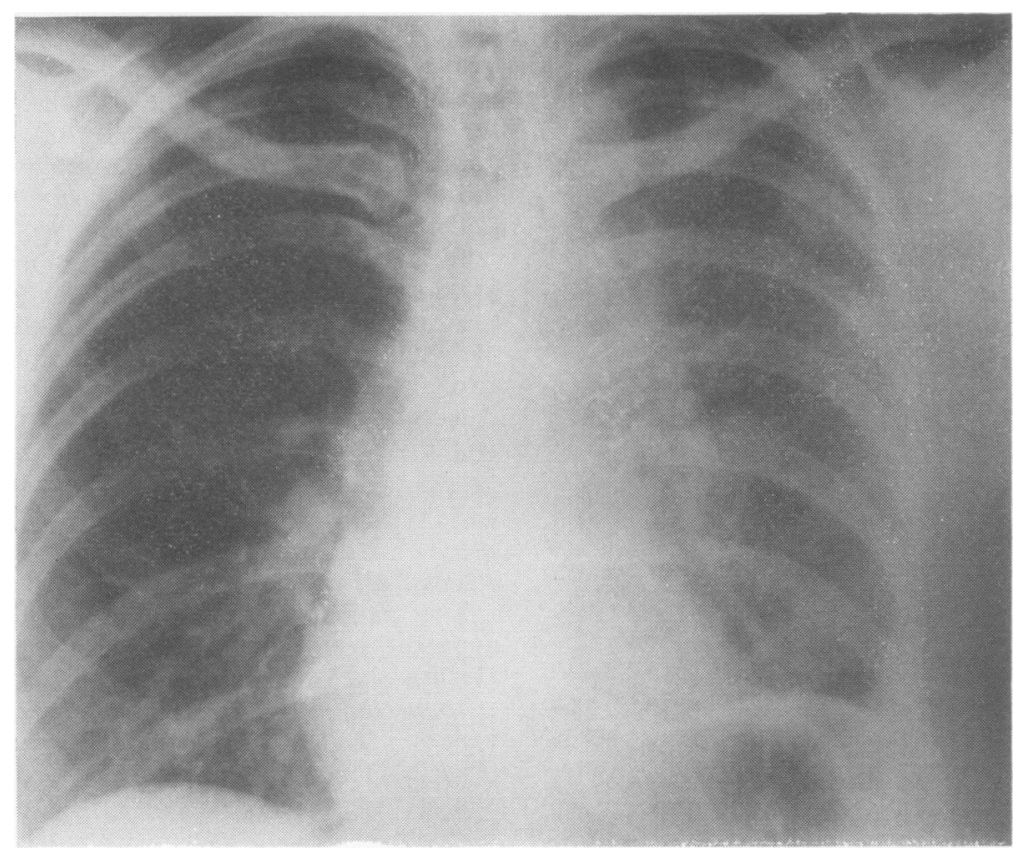

FIG. 3. Case 2. June 1967. 
graph showed some clearing and diminution in the hilar mass.

In December 1967 she felt reasonably well with no breathlessness; she had a slight cough but no sputum and was not nearly as tired as before. She now has good air entry into the left chest. Radiographs show a concentration of the gold grains (Fig. 4). The patient returned to work at the end of December, 1967.

RESULTS FROM GROUPS 1 TO 3 DESCRIBED ABOVE The results are shown in Tables $I$ and II.

T A B L E I

IMPLANTATION AT THORACOTOMY

\begin{tabular}{|c|c|c|c|c|c|c|c|}
\hline \multirow{2}{*}{ Histology } & \multicolumn{4}{|c|}{ Death (months) } & \multirow{2}{*}{$\begin{array}{c}\text { Sur- } \\
\text { vival } \\
\text { over 30 } \\
\text { mths }\end{array}$} & \multirow{2}{*}{ Total } & \multirow{2}{*}{ Alive } \\
\hline & 3 & 6 & 12 & 24 & & & \\
\hline $\begin{array}{l}\text { Undifferentiated } \\
\text { Squamous-celled } \\
\text { Oat-celled } \\
\text { Anaplastic } \\
\text { Adenoma } \\
\text { Not known } \\
\text { Adenocarcinoma }\end{array}$ & $\begin{array}{r}7 \\
18 \\
7 \\
1 \\
12 \\
3\end{array}$ & $\begin{array}{r}4 \\
10 \\
5 \\
- \\
13 \\
2\end{array}$ & $\begin{array}{r}4 \\
17 \\
6 \\
3 \\
10 \\
-\end{array}$ & $\begin{array}{r}4 \\
7 \\
- \\
8 \\
1\end{array}$ & $\begin{array}{r}2 \\
7 \\
1 \\
1 \\
12 \\
1\end{array}$ & $\begin{array}{r}21 \\
59 \\
21 \\
5 \\
1 \\
55 \\
7\end{array}$ & $\begin{array}{l}1 \\
2 \\
2 \\
1 \\
4 \\
1\end{array}$ \\
\hline Total & 48 & 34 & 40 & 23 & 24 & 169 & 10 \\
\hline$\%$ Survived & $71 \%$ & $52 \%$ & $28 \%$ & $20 \%$ & & & \\
\hline
\end{tabular}

Longest survival 10 years.

T A B L E I I

ENDOBRONCHIAL IMPLANTATION

\begin{tabular}{|c|c|c|c|c|c|c|c|}
\hline \multirow{2}{*}{ Histology } & \multicolumn{4}{|c|}{ Death (months) } & \multirow{2}{*}{$\left|\begin{array}{c}\text { Sur- } \\
\text { vival } \\
\text { over 30 } \\
\text { mths }\end{array}\right|$} & \multirow{2}{*}{ Total } & \multirow{2}{*}{$\begin{array}{l}\text { Alive } \\
\text { in } \\
4 \text { Yrs }\end{array}$} \\
\hline & 3 & 6 & 12 & 24 & & & \\
\hline $\begin{array}{l}\text { Undifferentiated } \\
\text { Squamous-celled } \\
\text { Oat-celled } \\
\text { Anaplastic } \\
\text { Not known } \\
\text { Adenocarcinoma }\end{array}$ & $\begin{array}{r}2 \\
4 \\
2 \\
1 \\
3 \\
-\end{array}$ & $\begin{array}{l}\overline{2} \\
\overline{-} \\
=\end{array}$ & $\begin{array}{c}\overline{5} \\
\overline{3} \\
1\end{array}$ & $\frac{\overline{1}}{\frac{2}{2}}$ & $\frac{1}{-}$ & $\begin{array}{r}3 \\
12 \\
2 \\
1 \\
10 \\
1\end{array}$ & $\begin{array}{l}= \\
\bar{z} \\
=\end{array}$ \\
\hline Tota! & 12 & 2 & 9 & 3 & 3 & 29 & - \\
\hline$\%$ Survival & $60 \%$ & $51 \%$ & $21 \%$ & $10 \%$ & & & \\
\hline
\end{tabular}

Longest survival $3 \frac{1}{2}$ years.

\section{DISCUSSION}

If an inoperable lesion is found at thoracotomy or bronchoscopy the question of any further treatment has to be considered. Once a patient develops symptoms, a course of radiotherapy is often given, though in a high proportion of cases the disease pursues a relentless course.

In this series there is a $28 \%$ one-year survival rate and a $20 \%$ two-year survival rate following gold grain implantation at thoracotomy.

Results from endobronchial implantation show a $21 \%$ one-year survival rate and a $10 \%$ two-year survival rate.
This compares favourably with the results of 101 patients reviewed at the Brompton Hospital who had a thoracotomy only, in whom the survival rates at one and two years were $10 \%$ and $1 \%$ respectively. Similarly, 47 patients who underwent thoracotomy and radiotherapy showed survival rates of $19 \%$ and $6 \%$ at one and two years.

We feel that interstitial irradiation has several advantages when compared with radiotherapy. The source of radiation can be placed exactly in the tumour, whether this is done at thoracotomy or through a bronchoscope. The treatment can be given at the time of operation and does not lengthen the patient's stay in hospital, whereas with radiotherapy a stay of three to six weeks may be required. Interstitial irradiation does not cause such marked malaise as radiotherapy and, in general, patients only complain of slight nausea and, on occasion, some transient dysphagia due to oesophagitis. Because the tumour size can be exactly determined at operation and the irradiation source can be placed within tumour tissue, the irradiation of healthy lung is reduced and we have not seen a case of pulmonary fibrosis following this treatment.

Many of these patients also showed improvement in general well-being following interstitial irradiation. Cough, pain, and malaise improved and weight increased. In many cases there were clinical and radiological signs of regression of the tumour with re-aeration of parts of the lung which had previously been collapsed. We have found that this method of treatment is of help from a psychological point of view, for the surgeon can quite truthfully tell the patient that the disease has been treated. There is no need for a course of radiotherapy, although this can be given as a supplement to interstitial irradiation, either at the time or when further symptoms develop. Indeed, a comparison of our survival rates with those of patients submitted to radiotherapy at the Brompton Hospital shows that interstitial irradiation produced better palliation (Bignall, 1956). In our series there were several patients in whom the pain of inoperable 'superior sulcus' tumours was relieved.

It is true that in a proportion of patients this form of treatment appears to make no difference. In many of these, the growth is often far advanced, and in others secondary spread is extensive. But some remarkable regressions and long-term survivals have been recorded. In our view, there is little to lose by giving patients this form of treatment, because the ill effects are minimal and there is the possibility of considerable benefit. Indeed, 
the pain of a thoracotomy is the same whether a source of radiation is placed in the chest or not, and it is of interest that post-operative complications such as empyema are rarely seen postoperatively.

A disadvantage of this treatment is the radiation hazard to the staff.

The maximum permitted whole-body dose of radiation is 5 rads a year or 100 mrads a week. Forty gold grains of average strength, $4.25 \mathrm{mCi}$ and half life $2 \cdot 7$ days, would produce the dosage rate shown in Table III.

T A B L E I I I

WHOLE-BODY DOSE OF RADIATION (mr./hour)

\begin{tabular}{c|c|c|c}
\hline Distance & $1 \mathrm{ft}(0.3 \mathrm{~m})$. & $2 \mathrm{ft}(0.6 \mathrm{~m})$. & $3 \mathrm{ft}(0.9 \mathrm{~m})$. \\
\hline At 0 hours & 400 & 100 & 45 \\
At 8 hours & 360 & 90 & 40 \\
At 24 hours & 320 & 80 & 35 \\
\hline
\end{tabular}

Thus a nurse who spent three periods of 15 minutes tending a patient in the first 24 hours following gold seed implantation-leaning close, within $2-3$ feet $(0 \cdot 6-0.9 \mathrm{~m}$.) of the source in the chest-may well receive a dosage which exceeds the safety level. There is also a greater risk to the surgeons' and assistants' hands when this form of treatment is used. Staff concerned in these operations and in the after-care have to take precautions as with any other treatment with a radiation source. The number of people in the operating theatre should be minimal and all must wear discs recording the amount of radiation to which they have been exposed. The patients must $b \overrightarrow{\vec{F}}$ nursed in a separate post-operative room, and there should be strict control of the time a nurse spends with the patient during the first six pos operative days.

With due precautions, as laid down by Radiation Protection Officer, we feel this hazaref does not exclude the use of this form of treatment$\vec{b}$

\section{CONCLUSION}

From the facts of this study, and taking int account the results of other workers in this field we feel that this treatment could be used with benefit more often in the treatment of patients with inoperable carcinoma of the bronchus.

We should like to thank Sir Clement Price Thomas. Mr. N. R. Barrett, Mr. W. P. Cleland, and Mr. ME Paneth for allowing us to investigate these patien and to operate on some of them; Dr. J. R. Bignall for helping with the survival figures; and $M$ J. Collyer for extracting so many piles of notes for us from the store.

\section{REFERENCES}

Ariel, I. M., Head, J. R., Langston, H. T., and Avery, E. E. (1949 The use of interstitial radon seeds and needles in inoperable lung cancer. Cancer (Philad.), 2, 581. Bignall, J. R. (1956). Bronchial carcinoma; effect of radiotherapy of
survival. Lancet, 1, 876.

Cliffton, E. E., Henschke, U. K., and Selby, H. H. (1958). Treatment of cancer of the lung by interstitial implantation. Cancer (Philad. $11,9$.

Hodt, H. J., Sinclair, W. K., and Smithers, D. W. (1952). Gun for interstitial implantation of radioactive gold grains. Brit. L Radiol., 25, 419.

Johnston, J. B., Cleland, W. P., and Howard, N. (1961). Treatment of carcinoma of the bronchus by interstitial irradiation. J. thorac cardiovasc. Surg., 42, 527. 